\title{
Solid Edge 3D Model of Synthesized Geared Slider Crank Mechanism with Variable Topology Features
}

\section{H. M. Naveen ${ }^{1}$, Shrinivas S. Balli² and Umesh M. Daivagna ${ }^{3}$}

${ }^{1}$ Assistant Professor, Department of Mechanical Engineering, RYM Engineering College, Ballari, Karnataka, India

${ }^{2}$ Professor, Department of Mechanical Engineering, Basaveshwar Engineering College, Bagalkot, Karnataka, India

${ }^{3}$ Professor, Department of Mechanical Engineering, Ballari Institute of Technology, Ballari, Karnataka, India

\section{Article Info}

Volume 7, Issue 3

Page Number: 632-637

Publication Issue :

May-June-2021

Article History

Accepted : 10 June 2021

Published : 16 June 2021

\section{ABSTRACT}

The paper introduces solid edge 3D model of synthesized geared slider crank mechanism. The synthesized mechanism exhibits the features of variable topology mechanism. This mechanism is modeled in solid edge software and presented. The gear connected to the crank provides the possibility of using it as an input and as well as output to the mechanism. The mechanism showcases the single input to multiple output variable topology features.

Keywords : Synthesized Geared Slider Crank, Variable Topology Mechanism, Solid Edge Model

\section{INTRODUCTION}

Solid Edge is a platform, where in, the synthesized mechanism can be built modeled and thus, the complete mechanism can be visualized virtually. This is a Computer Aided Design (CAD) program used for modeling of mechanisms, create drawings and animate the mechanism.

The fundamental aspect in kinematics is synthesis of mechanism. Synthesis can be classified as dimensional, type and number synthesis to perform various the tasks. Synthesis and Analysis are the two major categories of design process of mechanism. Synthesis process involves devising a mechanism to perform the desired task and analysis process involves functioning of the mechanism. When a mechanism is synthesized with some parameters, virtual model of the mechanism is built to study its working aspects. As complexity arises in building the real mechanism and testing, this calls for software based study of the mechanisms.

\section{LITERATURE REVIEW}

This text deals with the literature review on variable topology method adapted by different people working in this area. Balli and Chand [1] intimated that, an analytical method can be used to synthesize five bar mechanism with variable topology. The work was carried out for movement between extreme positions of the mechanism for function generation. 
Balli and Chand [2] proposed the complex number method and utilized it to synthesize the mechanism having five links for motion and path generation tasks with variable topology for movement between extreme positions. Balli and Chand [3] suggested an analytical method to synthesize planar seven link mechanism with variable topology for motion between two dead centers. Gadad, Umesh M. Daivagna and Shrinivas S. Balli [4] focused on synthesis of planar seven link mechanism using triad and dyad with variable topology for the task function generation. Daivagna and Balli [5] dealt with synthesis process of an off-set five link slider mechanism with variable topology. Ren-Chung Soong, Kuei-Shu Hsu and Feng-Tsai Weng [6] applied a geared seven-bar mechanism for mechanical forming presses. Daivagna and Balli [7] synthesized a variable topology seven-bar slider mechanism to have motion between two dead-center positions. Volken, Eres Soylemez and Engin Tanik [8] presented an analysis and synthesis method for a geared four-bar mechanism. Daivagna and Balli [9] worked on the synthesis of variable topology mechanism with five-bar slider for finitely separated positions. Prashant and Balli [10] reviewed the works on variable topology method. H. M. Naveen, Shrinivas S. Balli and Umesh M. Daivagna [11] dealt with synthesis of eight link gear mechanism for motion generation. H. M. Naveen, Shrinivas S. Balli and Umesh M. Daivagna [12] dealt with synthesis of In-Line Ten Link Gear Slider Mechanism of Variable Topology. Prashant and Balli [13] synthesized a seven bar slider for limiting positions using variable topology. H. M. Naveen, Shrinivas S. Balli and Umesh M. Daivagna [14] presented the behavior of mechanism using linkage software. H. M. Naveen, Shrinivas S. Balli and Umesh M. Daivagna [15] dealt with the functional aspects of ten link gear slider mechanism. H. M. Naveen, Shrinivas S. Balli and Umesh M. Daivagna [16] worked on Phase III operating conditions in variable topology mechanism.
H. M. Naveen, Shrinivas S. Balli and Umesh M. Daivagna [17] worked on alternative approaches in variable topology mechanisms. H. M. Naveen, Shrinivas S. Balli and Umesh M. Daivagna [18] dealt with transmission angles in eight link gear variable topology mechanism. H. M. Naveen, Shrinivas S. Balli and Umesh M. Daivagna [19] presented the solid edge 3D model of synthesized eight link gear variable topology mechanism. H. M. Naveen, Shrinivas S. Balli and Umesh M. Daivagna [20] presented the 3D model of ten link gear slider mechanism. Prashant and Balli [21] synthesized seven bar slider for dead center positions using variable topology method. $\mathrm{H}$. M. Naveen, Shrinivas S. Balli and Umesh M. Daivagna [22] dealt with synthesis of geared slider crank mechanism.

\section{SYNTHESIZED GEARED SLIDER CRANK MECHANISM WITH VARIABLE TOPOLOGY FEATURES}

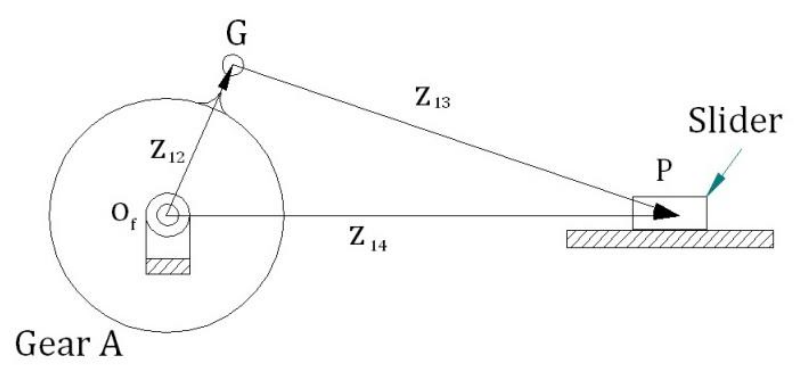

Figure 1. Schematic Representation of Geared Slider Crank Mechanism with Variable Topology Features

The Fig. 1 represents synthesized geared slider crank mechanism with variable topology features. The synthesis process is dealt with and the determined dimensions of the mechanism are considered in the modeling process of the mechanism using solid edge software [22]. The determined parameters of the mechanism are considered for modeling of the mechanism in solid edge designing software.

$\left|\mathrm{Z}_{12}\right|=\mathrm{O}_{\mathrm{f}} \mathrm{G}=22.5 \mathrm{~mm}$

$\left|\mathrm{Z}_{13}\right|=\mathrm{GP}=64.3 \mathrm{~mm}$

$\left|\mathrm{Z}_{14}\right|=\mathrm{O}_{\mathrm{f}} \mathrm{P}=62 \mathrm{~mm}$ 
$\left|\mathrm{P}_{12}\right|=\mathrm{P}_{1} \mathrm{P}_{2}=18 \mathrm{~mm}$

\section{MODELING OF SYNTHESIZED GEARED SLIDER CRANK MECHANISM WITH VARIABLE TOPOLOGY FEATURES IN SINGLE PLANE}

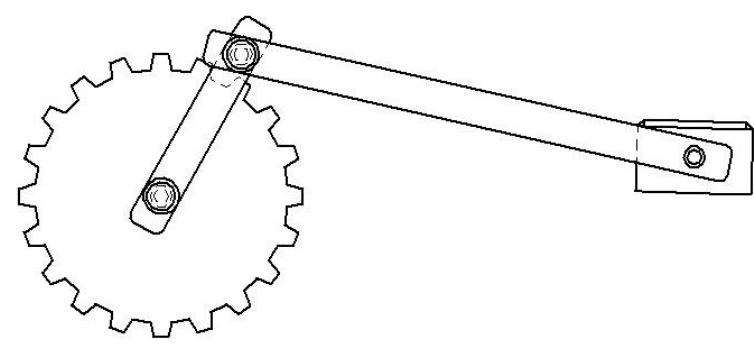

Figure 2. Schematic Representation of Geared Slider Crank Mechanism with Variable Topology Features Model in Solid Edge 2D Representation

The fig. 2 represents the modeling of the synthesized geared slider crank mechanism in solid edge software in two dimensions. This pictorial view resembles the mechanism which will be utilized in positioning of the links and orientation of the mechanism.

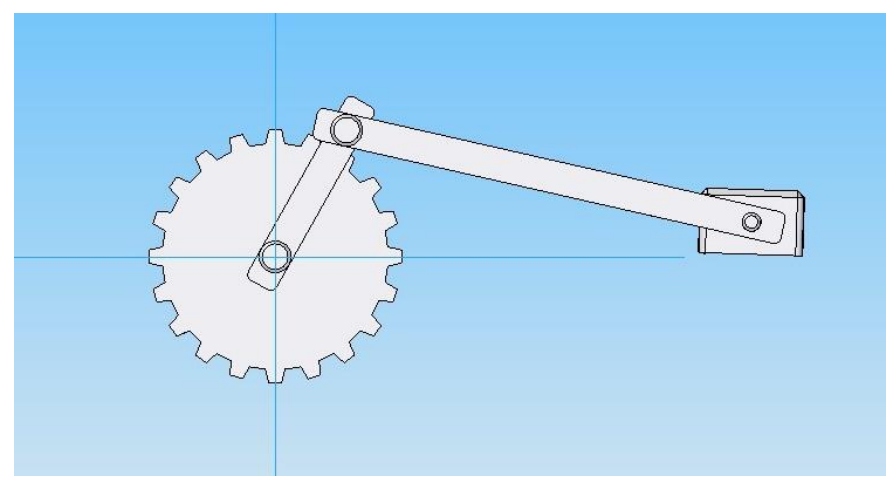

Figure 3. Schematic Representation of Geared Slider Crank Mechanism with Variable Topology Features Model in Solid Edge Front View Representation

The fig. 3 shows the model of the synthesized geared slider crank mechanism in solid edge software in two dimensions. The solid view can be considered to be made of materials like cast iron, aluminum, composites or wood as per the choice of the designer.
This view represents the solid view of the mechanism and aids to the look of solid links used in manufacturing the mechanism.

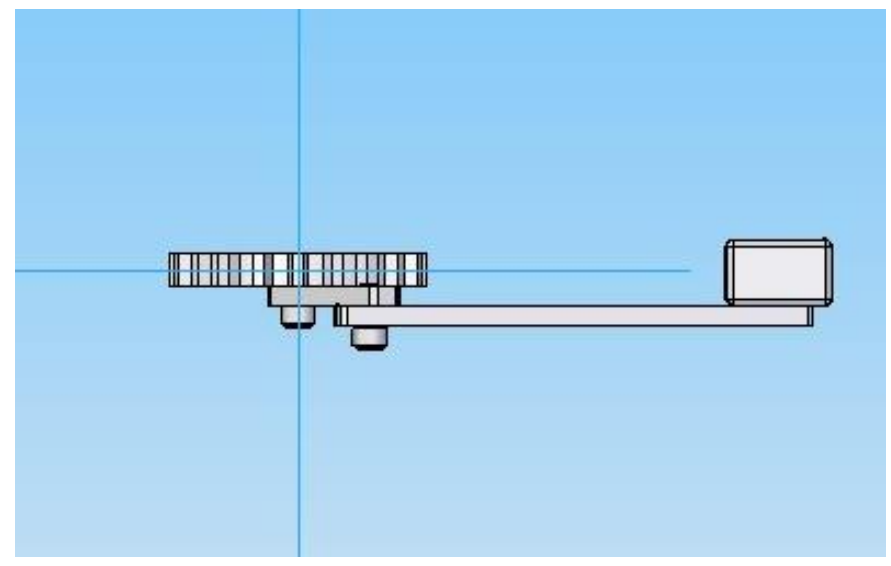

Figure 4. Schematic Representation of Geared Slider Crank Mechanism with Variable Topology Features Model in Solid Edge Top View Representation

The pictorial view represents the solid view of the mechanism and aids to the look of mechanism from top and its orientation. The fig. 4 shows the model of the synthesized geared slider crank mechanism in solid edge software in top view.

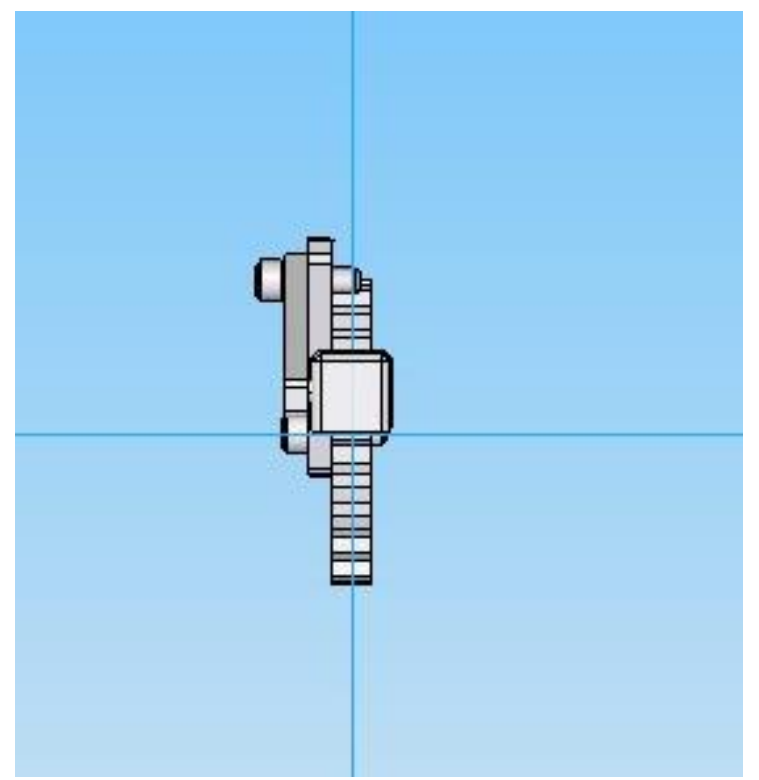

Figure 5. Schematic Representation of Geared Slider Crank Mechanism with Variable Topology Features Model in Solid Edge Side View Representation 
This pictorial view represents the solid view of the mechanism and aids to the look of mechanism from side view and its orientation. The fig. 5 shows the model of the synthesized geared slider crank mechanism in solid edge software in side view.

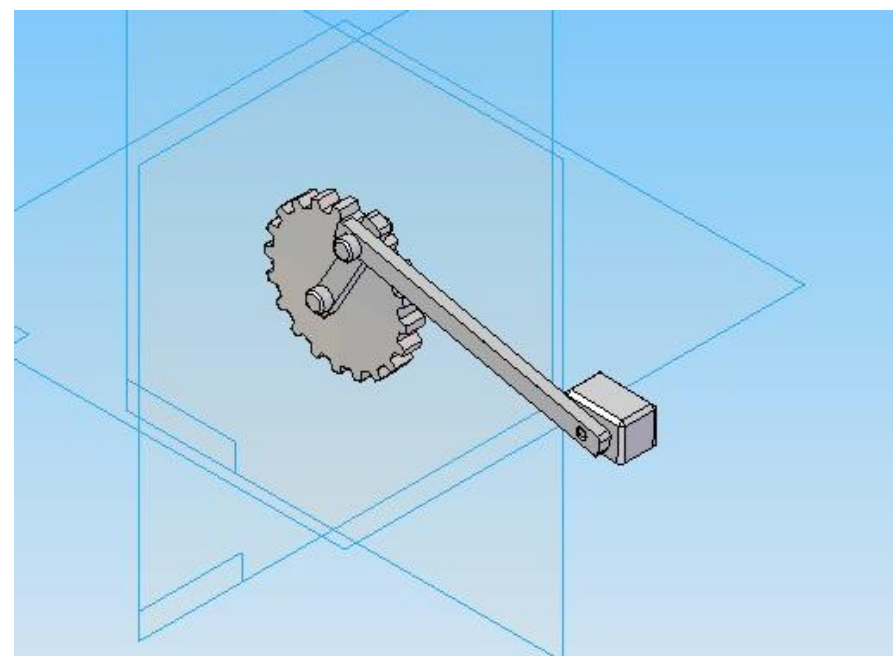

Figure 6. Schematic Representation of Geared Slider Crank Mechanism with Variable Topology Features Model in Solid Edge isometric View Representation

The fig. 6 and fig. 7 represents the model of the synthesized geared slider crank mechanism in solid edge software related to isometric view. This pictorial view represents the solid view of the mechanism and aids to the look of mechanism in three dimensions. This is one of the most useful view in which the complete assembly of the linkage can be seen and the study can be extended on the same.

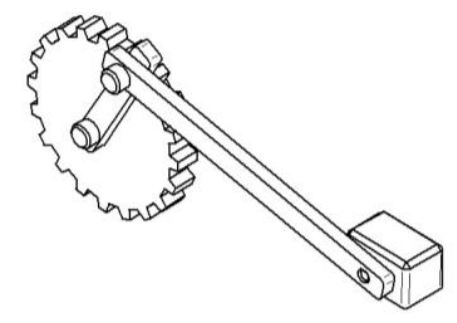

Figure 7. Schematic Representation of Geared Slider Crank Mechanism with Variable Topology Features Model in Solid Edge isometric View Representation

\section{FUTURE VIEW OF MODELING THE SYNTHESIZED MECHANISM IN SOLID EDGE}

The present paper on solid edge 3D model of synthesized geared slider crank mechanism demonstrates clearly that, a mechanism synthesized can be modeled in solid edge software to create different views of the design. Thus the models created can be exported to any of the analysis and simulation aspects and the work can be extended. The isometric view provides an insight among the design engineers so as to apply the parallel plane mechanism assembly to any of the existing earth moving equipments to carry out various tasks.

\section{CONCLUSION}

The study on modeling aspects of geared slider crank mechanism with variable topology features in assistance with solid edge software provides an insight to the design and development of synthesized mechanisms. Any synthesized mechanism can be taken into consideration for modeling. In order to visualize the working condition of the mechanism simulation can also be considered. The pictorial prediction of characteristics helps any designer to verify the observations and to develop a perfect operating mechanism.

\section{REFERENCES}

[1]. Shrinivas S. Balli and Satish Chand, "Synthesis of a five-bar mechanism with variable topology for motion between extreme positions (SYNFBVTM)," Mechanism and Machine Theory, vol. 36, no.10, pp. 1147-1156, 2001.

[2]. Shrinivas S. Balli and Satish Chand, "Five-bar motion and path generators with variable topology for motion between extreme positions," Mechanism and Machine Theory, vol. 37, no. 11, pp. 1435-1445, 2002. 
[3]. Shrinivas S. Balli and Satish Chand, "Synthesis of a planar seven-link mechanism with variable topology for motion between two dead-center positions," Mechanism and Machine Theory, vol.38, no. 11, pp. 1271-1287, 2003.

[4]. G. M. Gadad, Umesh M. Daivagna and Shrinivas S. Balli, "Triad and dyad synthesis of planar seven-link mechanisms with variable topology", National Conference on Machines and Mechanisms (NaCoMM '05), pp. 67-73, 2005.

[5]. Umesh M. Daivagna and Shrinivas S. Balli, "FSP Synthesis of an off-set five bar-slider mechanism with variable topology", National Conference on Machines and Mechanisms (NaCoMM '07), pp. 345-350, 2007.

[6]. Ren-Chung Soong, Kuei-Shu Hsu and FengTsai Weng, "A Programmable Geared Sevenbar Mechanism for Mechanical Forming Presses", Journal of the Chinese Society of Mechanical Engineers, Vol.29, No.1, pp.61-67, 2008.

[7]. Umesh M. Daivagna and Shrinivas S. Balli, "Synthesis of a Seven-Bar Slider Mechanism with Variable Topology for Motion between Two Dead-Center Positions", World Congress on Engineering, Vol. II, pp. 1454-1459, 2010.

[8]. Volken Parlaktas, Eres Soylemez and Engin Tanik, "On the synthesis of a geared four-bar mechanism", Mechanism and Machine Theory, Vol.45, Issue 8, August 2010.

[9]. Umesh M. Daivagna and Shrinivas S. Balli, "Synthesis of Five-Bar Slider Mechanism with Variable Topology for Finitely Separated Positions", Advances in Mechanical Engineering, vol.2011, 2011.

[10]. Prashant B. Tadalagi and Shrinivas S. Balli, “A Review on Mechanisms with Variable Topology (Revisiting the Variable Topology Mechanism)", IOP Conf. Series: Materials
Science and Engineering, Vol. 691, pp. 012047(1-9), 2019.

[11]. H. M. Naveen, Shrinivas S. Balli and Umesh M. Daivagna, "Two FSP Synthesis of Eight Link Gear Mechanism for Motion Generation with 9R-1G Joints", International Journal of Engineering Applied Science and Technology, Vol. 5, No. 3, pp. 288-294, 2020.

[12]. H. M. Naveen, Shrinivas S. Balli and Umesh M. Daivagna, "Kinematic Synthesis of In-Line Ten Link Gear Slider Mechanism of Variable Topology with 12R-1G-1P Joints", International Research Journal of Engineering and Technology, Vol. 7, No. 8, pp. 605-610, 2020.

[13]. Prashant B. Tadalagi and Shrinivas S. Balli, "Limiting Positions Synthesis of Seven Bar Slider Automated Fiber Placement Mechanism for Motion Generation using Variable Topology", International Journal of Mechanical and Production Engineering Research and Development (IJMPERD), Vol. 10, Issue 3, pp. 13297-13308, 2020.

[14]. H. M. Naveen, Shrinivas S. Balli and Umesh M. Daivagna, "Study of Characteristic Behavior of Synthesized Variable Topology Mechanism using Linkage Software”, GIS Science Journal, Vol. 7, No.8, pp. 160-166, 2020.

[15]. H. M. Naveen, Shrinivas S. Balli and Umesh M. Daivagna, "Functional Aspects of Synthesized In-Line Ten Link Gear Slider Mechanism of Variable Topology using Linkage Software", International Research Journal of Engineering and Technology, Vol. 7, No.9, pp. 3281-3286, 2020.

[16]. H. M. Naveen, Shrinivas S. Balli and Umesh M. Daivagna, "Possible Configurations and Coupler Curves of Eight Link Gear Variable Topology Mechanism in Phase III Operating Condition", International Research Journal of 
Engineering and Technology, Vol. 7, No. 11, pp. 502-509, 2020.

[17]. H. M. Naveen, Shrinivas S. Balli and Umesh M. Daivagna, "Alternative Approaches in Variable Topology as Applied to Degree(s) of Freedom and Modes of Operation in Mechanisms", International Journal of Advances in Engineering and Management, Vol. 2, No. 9, pp. 442-449, 2020.

[18]. H. M. Naveen, Shrinivas S. Balli and Umesh M. Daivagna, "Transmission Angles in Synthesized Eight Link Gear Mechanism of Variable Topology with Characteristic Output", International Journal of Engineering Sciences \& Research Technology, Vol. 10, Issue 2, pp. 60-68, 2021.

[19]. H. M. Naveen, Shrinivas S. Balli and Umesh M. Daivagna, "Solid Edge 3D Model of Synthesized Eight Link Gear Variable Topology Mechanism", International Journal of Computer Techniques, Vol. 8,Issue 2, pp. 163170, 2021.

[20]. H. M. Naveen, Shrinivas S. Balli and Umesh M. Daivagna, "Solid Edge 3D Model of Synthesized In-Line Ten Link Gear Slider Variable Topology Mechanism", International Research Journal of Engineering and Technology, Vol. 8,No. 4, pp. 3056-3061, 2021.

[21]. Prashant B. Tadalagi and Shrinivas S. Balli, "Dead Centre Positions Synthesis off offset Seven Bar Slider Mechanism for Motion Generation using Variable Topology", GIS Science Journal, Vol. 8, No.5, pp. 1613-1620, 2021.

[22]. H. M. Naveen, Shrinivas S. Balli, Umesh M. Daivagna, " Kinematic Synthesis of 3R-1P Geared Slider Crank Mechanism with Variable Topology Features for Motion Generation", International Journal of Scientific Research in Science, Engineering and
Technology(IJSRSET), Volume 8, Issue 3, pp.317-322, May-June-2021.

\section{Cite this article as :}

H. M. Naveen, Shrinivas S. Balli and Umesh M. Daivagna, "Solid Edge 3D Model of Synthesized Geared Slider Crank Mechanism with Variable Topology Features", International Journal of Scientific Research in Computer Science, Engineering and Information Technology (IJSRCSEIT), ISSN : 2456-3307, Volume 7, Issue 3, pp.632-637, May-June2021. Available at Journal URL : https://ijsrcseit.com/CSEIT2173135 